\title{
BENJAMIN PENSADOR DO BARROCO: ACÍDIA E PSICANÁLISE
}

Olgária C. F. Matos

\section{RESUMO}

O presente artigo procura mostrar as razões pelas quais Walter Benjamin analisa o conceito de razão à luz de seus derivados constitutivos: o luto, a acídia, a melancolia e a alegoria. Distanciando-se do dualismo freudiano que postula uma separação entre luto e melancolia, a sinonímia benjaminiana é o fundamento em que o filósofo inscreve o retorno da acídia medieval no século XVII, isto é, ao tempo da revolução cartesiana e galilaica, no horizonte da psicanálise.

Palavras-chave: Psicanálise. Acídia. Melancolia. Revolução.

\section{BENJAMIN THINKER OF BAROQUE: ACEDIA AND PSYCHOANALYSIS}

\begin{abstract}
This article intends to show the reasons by which Walter Benjamin analyzes the concept of reason in light of its constitutive derivatives: the grief, the acedia, the melancholy and the allegory. Distancing himself from the Freudian duality that demands a separation between mourning and melancholy, the benjamian synonym is the foundation in which the philosopher register the return of the medieval acedia from the XVII century, at the time of the Cartesian and Galilean revolution, in the horizon of psychoanalysis.
\end{abstract}

Keywords: Psychoanalysis. Acedia. Melancholy. Revolution.

Já se disse da metafísica ser ela uma "paranoia organizada", um sistema de suspeitas face à aparência, sempre enganosa, das coisas. Separando sensível e inteligível, essência e aparência, imaginário e real a "Filosofia da Consciência" de estilo cartesiano exorcizou os fantasmas da visão por uma fisiologia do olho e pelo estudo algébrico dos ângulos da visão. Se a filosofia procura vencer a opacidade do mundo, a psicanálise nos indica o que resiste ao conhecimento, obstáculos que não procedem apenas da natureza que não cede nunca inteiramente à ciência, mas sobretudo do próprio Eu, uma vez que a consciência não é capaz de proscrever a “ sombra da razão" que a acompanha como seu outro ameaçador, em particular as 
ilusões. Foi Freud quem mostrou de que maneira esta escapa ao campo do verdadeiro e do falso porque diz respeito a desejos. Eis por que ambas, Filosofia e Psicanálise estudam as representações imaginárias e sua constituição, as maneiras pelas quais irrealidades criam realidades.

Assim, no ensaio "Uma neurose demoníaca do século XVII", Freud (1923/1976b) analisa a obra do pintor Christoph Haizmann que em agosto de 1667 apresenta um quadro de convulsão e afirma ter concluído um pacto com o demônio. Com isso, o pintor the concedia seu corpo e sua alma durante nove anos, compromisso que devia expirar em setembro de 1677. O artista passava por uma crise de criação na sequência da perda do pai. O demônio tinha a peculiaridade de possuir dois seios, que Freud interpreta como uma atitude feminina do pintor com respeito ao pai, de onde os nove meses corresponderem à gestação e a seu renascimento, com o que daria um filho a seu pai, circunstância que Freud considera um estado depressivo, o demônio operando a substituição da figura paterna. Para pôr um fim a seus tormentos, para o que o pacto não havia contribuído, ao contrario, intensificado-os em vez de aliviá-los, o pintor privado da capacidade de pintar não tem mais como prover sua subsistência e, assim, decide abandonar a vida secular, ingressando em uma ordem religiosa. Cessam, então, suas angústias, e Freud enfatiza que a neurose era devida sobretudo a suas dificuldades de sobrevivência material, desconsiderando a questão do demoníaco.

O século XVII é o século do barroco, o da desestruturação da ciência antiga, da perda da centralidade do divino, substituídos pela ciência moderna. Neste sentido Koyré (1967) observa: "durante os séculos XVI e XVII o espírito europeu sofreu ou realizou - uma revolução espiritual muito profunda, revolução que modificou os fundamentos e os próprios quadros de nosso pensamento e cuja raiz e fonte é a ciência moderna. Essa revolução que também se denominou 'crise da consciência européia' mostra que o desenvolvimento da nova cosmologia substituiu o mundo geocêntrico dos gregos e o mundo antropocêntrico da Idade Média pelo universo descentrado da astronomia moderna. E certos historiadores, interessados principalmente nas implicações sociais dos processos espirituais, insistiram sobre a conversão do espírito humano da teoria para a práxis, da scientia contemplativa para a scientia activa que transformou o homem de espectador da natureza em seu possuidor e senhor. Outros ainda viram seu traço mais característico na 
secularização da consciência, isto é, na substituição da preocupação com o 'outro mundo' pelo interesse por 'este mundo'. [...]. As mudanças estruturais produzidas pela revolução do século XVII podem ser reduzidas a dois elementos principais e estreitamente ligados entre si: a destruição do cosmos e a geometrização do espaço." (Koyré, 1-3, Du monde clos à l'unviers infini (ed PUF, Paris, 1967). A percepção barroca desse deslocamento é bem sensível na interpretação que Benjamin faz da ideia de um Deus absconso. Com o fim das representações divinatórias, o espaço esvaziado divino será preenchido com a idéia de representação para explicar o homem, e assim, o barroco que lhe é contemporâneo, voltava-se sobretudo para a dimensão política, a secularização sendo um dos sintomas dessa postura diante da coerção da época, inclusive a dogmática e a religiosa. O barroco quer a expansão do pensamento, sua libertação através de rebus e tropos, segundo uma razão heterodoxa, revestida de adereços e ornamentos com respeito à hegemonia cristã, ao mesmo tempo emancipada das heteronomias, e ,marcada por elas.

Com efeito, o século XVII é o século de Descartes e da geometrização do espaço que começa, no entanto, com um dado biográfico cujo significado se expressará na obra do filósofo. Quando jovem, Descartes se apaixonou por uma jovem que "era um pouco estrábica" e cujos "olhar extraviado" ficou tão ligado a sua paixão que "muito tempo depois, ao ver pessoas estrábicas, [ele] se sentia inclinado a gostar delas mais que de outras pessoas." (Cf. Descartes, "Lettre à Chanut" de 6/06/1647, in Oeuvres et Lettres, ed Gallimard, 1953, 277.) O estrabismo desdobra os objetos, envolvendo-os com uma ambiguidade fluida, aproximando a percepção do sonho. Na primeira "Meditação" de suas Meditações Metafísicas, Descartes escreve: "Quando penso mais detidamente nisso, vejo que nunca se pode distinguir por marcas seguras a vigília do sono, de tal modo fico pasmo, e este estupor quase confirma a opinião de que estou dormindo." (Cf. "Meditações", in Pensadores, trad. José Guoinsburg e Bento Prado Jr., ed Abril Cultural, 1973, 94.) Pode-se mitigar a dúvida cartesiana, sua dúvida hiperbólica com respeito ao real, mas ela nada mais faz que levar ao extremo o desconcerto em julgar, em distinguir o dentro e o fora, o percebido e o sonhado, na qual a experiência da angústia se converte em meio de defesa contra ela, transformando-se em experiência metafísica, justamente porque esta é o resultado da luta metódica para atribuir às coisas algo mais que um ser 
apenas de razão, independente do espírito que as pensa, esforço para dar corpo a fantasmas que, se não carecem de consistência, devem ter uma existência na representação. Mas trata-se de uma luta patética porque, entregue a representações, o sujeito é vitimado por um demônio, pelo gênio maligno que o invade e maltrata com seus jogos de espelho e ilusões, em que nada parece real, nem o mundo, nem o corpo, e o Eu é ameaçado de dissolução por um duplo que o persegue com suas intenções maléficas. (Cf F. Pasche, "Métaphysiqwue et inconscient", Le sens de la psychanalyse, Puf, 1998). As representações nos entregam a um universo de pavor porque abstrato e impessoal, sem telos, sem finalidade, realidade exclusivamente psíquica, sem exterior. Mundo sem extensão e, assim, sem distâncias. Vertigem substituída por um Deus infinito e bom, o Deus Veraz que garantirá a realidade das representações centralizadas no Eu pensante e proverá a existência do mundo exterior pelo domínio técnico e científico do mundo.

Ao século XVII, com seu otimismo científico, pertenceu também Pascal cuja solidão dos espaços infinitos enchia a alma de angústia e pavor, pois, no infinito, onde encontrar o centro? Eis por que Benjamin observa: "O perigo de cair dos píncaros da ciência no abismo profundo do espírito barroco é grande e não deve ser desprezado. Encontramos, frequentemente, nas tentativas improvisadas de apreender o sentido dessa época, uma sensação característica de vertigem, produzida pela visão de um universo espiritual dominado por contradições." (Origem do Drama Barroco Alemão, trad. Sérgio Paulo Rouanet, ed Brasiliense,1984, 78-79). Vertigem e desestruturação se expressam também em Hamlet: "ser ou não ser" é a questão acerca do lugar que o homem ocupa no universo descentrado e sem objetivo final. Hamlet, o "príncipe do pensamento especulativo", o grande trágico do acaso é perseguido por fantasmas que perturbam sua capacidade de raciocinar. Ele é aquele que suspende a ação para longas reflexões quando deveria agir com rapidez, e age quando se tratava de pensar. Hamlet é perturbado pelo demônio que tem poder sobre os melancólicos: "talvez o demônio, abusando de minha inconstância e fragilidade, queria me enganar." : "na tristeza", escreve Benjamin, "Satã é a tentação. É quem nos inicia na ascese a um saber, o fundamento da conduta a ser punida. Se Sócrates se engana ao ensinar que o conhecimento do bem conduz a praticá-lo, isto é ainda mais verdadeiro com relação ao conhecimento do mal. E esse saber não é a luz interior, o lumen naturale que surge da noite da 
tristeza, mas uma luz subterrânea que brilha do fundo das entranhas da terra. Essa luz tênue ilumina naquele que rumina seus pensamentos o olhar penetrante $\mathrm{e}$ subversivo de Satã" (Benjamin, op cit. p 247). Demônios assediam os melancólicos, propensos a visões e a alucinar fantasmas.

Fantasma é o que não permite propriamente uma representação porque the falta o objeto da representação, ele é a ausência e o retorno de algo desejado, mas inexistente. Este fantasma é um duplo sem referente externo que existe como delírio, é representação que se toma pela própria coisa. Se o real é o que pode se modificar, o que se abre aos possíveis, a alucinação não tem futuro, é inalterável e fechada sobre si mesma. Não por acaso, o fantasma é uma representação que se faz na ausência de objeto da representação e sem ele. No Dictionnaire Universel de 1690 lê-se: "representação se diz, [no âmbito eclesiástico] de um falso ataúde de madeira, recoberto por um tecido mortuário, em torno ao qual se acendem velas quando se realiza o serviço por um morto." (Cf http:gallica.bnf.fr) Neste sentido, falsos ou verdadeiros, reais ou imaginários, todos os túmulos são vazios, são monumentos abandonados por aqueles que se honra neles.

Assim, no caso do pintor que substituiu a ausência paterna por demônios, esta substituição foi a maneira de lutar contra sua ausência. ${ }^{1}$ Em Homero o eidolon é fantasma, sombra, simulacro. Quando Pátroclo morto aparece em sonhos a Aquiles, é o própria amigo, sua voz, seus olhos formosos, seu cinturão entalhado, suas vestimentas, é um fantasma tão semelhante a ele que Aquiles estende os braços em vão para retê-lo. A psyché desaparece como fumaça e Aquiles desperta em lástimas: "Então, também na morada de Hades há uma alma (psyché), ou uma sombra (eidolon) de que se retirou o espírito." (Cf Iliada,canto XXIII, vs 103-104. Na tradução de Haroldo de Campos: " Céus! No Hades há psiquês e ícones, mas inânimes, sem vida.", ed. ARX, SP:2008, p395). A psyché reproduz o corpo mas à maneira de um fantasma. Esta psyché é um eidolon que inclui a imagem do sonho (oneiros), a sombra (skya), a aparição sobrenatural (phásma).

1 Ao refletir sobre as diferentes maneiras de representar as coisas, Platão nos ensina que em primeiro lugar o eidos, a forma eterna, algo sempre igual a si mesmo, algo que não é nem coisa, nem simples idéia, nem duplicação do sensível, nem produto do espírito, senão que é o inteligível que se deve ter por real, se se quiser que o saber se diferencie da opinião, como o ser difere do devir. Derivando de eidos há o eidolon, outro "aspecto" de uma coisa, não mais a verdadeira essência, mas seu substituto sem valor, a imagem. E sinônimo de eidolon o eikon, a imagem enquanto se assemelha (éoika) ao modelo de que é cópia. E por fim, o substituto mais frágil, o fantasma, o que passa por cópia sem o ser, a ilusão que é esse nada que pode imitar qualquer coisa sem a coisa.

Professora da Universidade Federal de São Paulo (UNIFESP). Pós-Doutorado pela Ecole des Hautes Etudes en Sciences Sociales, França. Brasileira, residente em São Paulo - SP. Email: 
Demônios são fantasmas que Freud inscreve na neurose. Mas seria interessante lembrar que os demônios perturbadores da visão e do pensamento já assediavam o espírito de eremitas e monges, de maneira a que o fato biográfico narrado por Freud pode ser relacionado à acídia medieval, uma vez que os demônios que assombravam o anacoreta nos desertos de Alexandria ou nos mosteiros medievais manifestam o desespero e a inquietação que fazem parte da vida daqueles que decidiram distanciar-se das solicitações do mundo. Além disso, a representação de um diabo figura o duplo do próprio Sujeito. Um corpo de demônio com seios de mulher significa, no século do racionalismo filosófico e científico, o recalcado da civilização iluminista, a acídia como desconhecimento do sujeito em relação a seu próprio corpo. Pois se o Sujeito para legitimar seu comando sobre o mundo necessitou desfazer-se do corpo e de suas paixões, da psicologia e da memória, da sensibilidade e da imaginação perturbadoras do conhecimento objetivo, esse Sujeito abstrato, puro pensamento que se pensa a si mesmo, separou o corpo da alma; e por isso,toda a metafísica ocidental fundada no Sujeito, encarcerou para a eternidade o Sujeito no seu próprio eu como punição por sua idolatria. (Cf. Adorno, "Para uma Metacrítica da Razão Prática”, in Dialética Negativa,trad. Marco Antonio Casanova, ed Zahar, RJ, 2009). Neste sentido, ao mencionar os “ insensatos" que deliram, para deles fazer triunfar a certeza do Cogito, e a fim de enfatizar a loucura daqueles que desconhecem o raciocínio dedutivo, indutivo ou a intuição matemática, Descartes procura significar que o delírio é próprio daqueles incapazes de desenvolver uma consciência atenta e, assim, encontram-se em estado de semivigília, na sonolência da razão. Se somente uma consciência atenta e concentrada pode fornecer um esclarecimento do objeto de conhecimento, a percepção desatenta só poderia ser delirante. Todo o esforço racionalista é o de encontrar uma maneira de estarmos certos de sermos normais. Assim, na Primeira Meditação, Descartes radicaliza os riscos dos erros dos sentidos, da imaginação e da memória para melhor se assegurar de uma verdade quando com ela nos defrontarmos. Para isso, Descartes se dispõe a duvidar de tudo, podendo tudo negar, exceto que suas mãos, seus cabelos sejam efetivamente seus. Conclui então: "E como poderia negar que estas mãos e este corpo sejam meus? A não ser, talvez, que eu me compare a esses insensatos, cujo cérebro está de tal modo perturbado e ofuscado pelos negros vapores da bile que constantemente asseguram que são reis quando são muito 
pobres, que estão vestidos de ouro e de púrpura quando estão inteiramente nus, ou imaginam ser cântaros ou ter um corpo de vidro. Mas que! São loucos e eu não seria menos extravagante se me guiasse por seus exemplos." (Descartes, Primeira Meditação, op cit. P 94). E na Recherche de la Vérité e na Pirmeira Meditação, Descartes enumera diversas figurações do delírio, quando os loucos imaginam serem colmeias ou terem uma " cabeça de argila" ou o corpo ser uma "abóbora": " esses melancólicos" , escreve, "[...] pensam ser colméias ou ter alguma parte do corpo de tamanho enorme." (op cit , 94). No Drama Barroco Alemão, Benjamin considera a "drenagem do sujeito" para o exterior, o esvaziamento do sujeito convertido em puro pensamento, com a perda do mundo interno e externo , resultando em delírio, delírio de grandeza quando o doente se vê "de tamanho gigante". Delírio de orgulho na Idade Média, a loucura é, na modernidade, desvario da razão: os muito pobres "acreditam-se vestidos de ouro ou púrpura". Vaso de barro, colmeia ou cabeça de argila, o corpo extravagante é oco e vazio, como uma abóbora ressecada e esvaziada de sua substância. Um homem cujo corpo é de vidro é um ser descarnado em uma fantástica sublimação, como o desejo insensato "de ser um corpo de uma matéria tão pouco corruptível, como os diamantes, ou ter asas para voar, como os pássaros." (Terceira Parte do Discurso do Método, col. Os Pensadores, op cit. 51). Se o corpo de barro é opaco e oco, o vidro é matéria imaterial que a transparência espiritualiza. O louco é um "inspirado", diz coisas cheias de sabedoria, mas não deste mundo. A negação epistemológica do corpo o corpo é de vidro - resulta em um corpo descarnado. A loucura é pois o desconhecimento pelo Sujeito de seu próprio corpo e de si mesmo, o louco não habita o corpo que tem, não vê o que é, e vê o que não é. No que diz respeito ao pintor, seu delírio, que decorre do trauma da perda, é delírio da perda de sua identidade, delírio que cria personagens inexistentes em lugar dos quadros que o artista não consegue mais pintar, crise que indiferencia real e imaginário, masculino e feminino, o corpo e a alma, a arte e a vida. Neste sentido, compreende-se que o trabalho de Freud se abre a uma reflexão sobre o demoníaco moderno em que são analisados os fantasmas posteriores ao advento da psicologia e da racionalização, posteriores também à formalização das relações sociais e ao desencantamento do mundo. Suas análises do inconsciente se aliam às questões culturais decorrentes das humilhações pelas quais o homem passou na perda da centralidade da Terra e 
com a "morte de Deus", com Copérnico, Galileu, Kepler, Darwin, Marx e Nietzsche. O que significa que o "olhar visionário" e seus fantasmas foi confinado na categoria de "erros da visão", a ser corrigido pela ciência, pelo cálculo geométrico-algébrico da luz e por uma fisiologia do olho, no caso de Descartes. Freud indica o perigo sempre iminente de que o Eu consciente e racional, assombrado por rastros mnêmicos, alucine, porque, na alucinação, o que se representa quer se fazer passar pelo próprio objeto, coincidindo com ele. De onde os dispositivos racionalistas de controle do conhecimento.

Com efeito, o século XVII é o da efetivação do dualismo e, em Descartes, o louco que diz ter corpo de vidro ou uma cabeça de abóbora, mistura o corpo e a alma, sendo o delírio demoníaco uma das variantes da melancolia que é justamente a circunstância de o melancólico ser ao mesmo tempo ele mesmo e seu contrário, ele mesmo e um Outro. Por isso trata-se de uma crise de identidade ou de crise em relação à alteridade. O que é mais perturbante não é a alteridade em geral, mas nossa própria alteridade, a parte de nós mesmos que compõe o Outro de si. Encontra-se aqui o tema do Unheimlich (Freud, 1919/1976 a) a alteridade fazendo parte do heimlich, do mais familiar a nós mesmos, mas que nos é estrangeiro, o que se encontra próximo demais para ser captado inteiramente e assim ser dominado ou compreendido.

Há ainda no caso do pintor Crhistoph Haizmann duas questões essências para a filosofia, a questão da pintura - quer dizer, do fantasma e da mímesis, por um lado - e a do tempo, de outro. Quer dizer, a questão da imitação (pintura) e da morte (a perda do pai) são inseparáveis não apenas porque as visões aparecem depois da morte do pai do pintor com a impossibilidade de criar, mas porque se trata também de um presente temporal que não é mais a dimensão de uma abertura e inacabamento, mas de um presente que não consegue mais passar, uma clausura decorrente do desaparecimento paterno.

A ameaça do retorno ao indeterminado, ao informe, ao demoníaco e à morte são a experiência do deinos, do terrífico e do pânico dos vivos com os espíritos dos mortos. Assim como os demônios dizem respeito a ausências, também a pintura é inquietante, pois nela o princípio de realidade vacila, uma vez que se trata de uma irrealidade que se produz como realidade: "É neste ponto que se faz o pacto faustiano entre o pintor e o demônio. A substância da vida de Christoph Haizmann é 
a beleza, e a forma é a alienação, entendida aí como a impossibilidade de integração no dia a dia comum do século XVII.". (Hardt Jr., 2013, 136). E continua Hardt Jr., "O pintor é apresentado por Freud como um órfão que sofre em um mundo antagônico à experiência de criação estética, é o portador de uma sensibilidade inábil em integrar-se ao modo de vida de sua pequena cidade natal. Em busca de adaptar-se ao mundo, ele procura uma forma de vida que 'resolva a oposição entre o espírito e a sensualidade, a arte e a vida, a existência artística e o mundo em volta'. (Marcuse, apud Kangussu, I., in Kriterion, vol.46 no.112, BH, Dec. 2005)."

Integração impossível, uma vez que o acontecimento vivido como traumático diz respeito ao próprio ato de pensar, por isso, evocar a história de uma neurose demoníaca é evocar a própria história do pensamento, das obras de pensamento que são as obras de arte, e a história da vida intelectual acaba se revelando como a culpa de pensar, mistura de pudor e de pânico que conduzem à auto-censura. Entre a potência criadora e a esterilidade, manifesta-se a dualidade da resistência e da depressão, a impossibilidade de criar e a criação desses demônios interiores. Se a separação entre vida intelectual e mundo externo se converte na forma tranquilizadora da separação sujeito e objeto, é isso justamente que falta no endemoniado: "O desejo de ultrapassar esse sofrimento mental é ativado pela ideia da existência de um estado anterior de harmonia entre subjetividade artística e mundo exterior, forma e realidade, sujeito e objeto." (Hardt Jr. 2013, 136). Há ainda a referência ao demônio alado de seios, demônio feminino que pode ser compreendido como o duplo da Melancolia I de Dürer, demônio feminino analisado por Freud, uma vez que, sendo ainda um enigma, da psicologia feminina só é possível uma aproximação através dos poetas, anjo feminino em Dürer. $O$ melancólico não pode distinguir anjos e demônios, o bem e o mal, por um déficit na produção de sentido, déficit de vida intelectual. E os demônios internos, em suas diferentes aparições, são a forma de rebelião do sujeito pensante, é insurgência do pensamento contra si mesmo: Assim, em uma "primeira aparição, o demônio teria se apresentado como um bom cidadão, honesto, de barba castanha, usando capa vermelha. E com um bastão e com um cão preto a seu lado. Aos poucos, este demônio vai se tornando horripilante, adquire chifres, garras de águia, e a capa transforma-se em asas de morcego. Posteriormente, em outra aparição, desta vez em uma capela, o demônio ganha a forma de um dragão alado com seios 
balouçantes. Se Deus é a representação do pai, o Demônio, sua antítese, é o feminino, e assim não lhe é tão distante, sendo até muito próximos em sua natureza ${ }^{2}$. Talvez sejam idênticos'. (Hardt Jr., 2013, 134). Além da identificação deus-demõnio, há a questão da fuga do mundo para um convento, a maneira de Christoph Haizmann resolver as dificuldades de sua vida. O convento é um comptentus mundi, mas ao qual o pintor é levado como que pelo demônio e, assim, o demônio em parentesco com a vida espiritual, pois a vida pública ou em público, a do mundo do trabalho, requer mostrar-se. Retirar-se para a vida conventual é, simultaneamente, uma recusa de ser visto pelo Outro, e uma fuga para a vida interior, é o desejo de resguardar segredos e o mais íntimo fora do alcance social.

A análise do caso levada a termo por Freud, que não menciona as questões culturais e a acídia, surpreende, uma vez que ele era o grande intérprete da história da melancolia. Freud não se refere à importância e presença dos demônios no Ocidente cristão, aos anacoretas e eremitas. Demônios e acídia, portanto, acídia que se manifesta não pela "preguiça do coração", nem pelo desejo de dormir mas, bem ao contrário, por pensamentos obsedantes e dolorosos: o deserto é o martírio interiorizado. Santo Antão é tomado por pensamentos que não o deixam em paz, em meio ao delito de instabilidade, a instabilitas da alma. Este mal-estar, esta inquietude de não conseguir ficar no lugar em que se encontra, de pensamentos que rodopiam no cérebro do monge e que o angustiam no esforço de querer esvaziá-lo, são os sintomas do que afasta o santo de Deus. A acídia é um demônio que arrasta o monge para fora de sua cela de meditação. Ou que o leva para o mosteiro. A acídia é o mal que ameaça os solitários mas também uma das modalidades de pensamento.

A história da solidão tem seus antecedentes gregos. Demócrito, em Adbera, se retira para as montanhas, e sempre perto de monumentos aos mortos, Tucídides foi para uma floresta da Trácia para escrever suas Histórias, Eurípides se refugiou em uma caverna escura para escrever suas tragédias. Ninguém pode viver em solidão se não for apto a ela, se não tiver temperamento para isso, um habitus do corpo e da alma. Neste sentido, Hardt Jr. (2013) observa: "As aparições horrendas demoníacas, esta agonia psíquica, segundo Freud, seriam devidas à angústia, ou à transformação direta da libido não utilizada. Na verdade a libido não pode ser

2 Pois Lúcifer é um anjo de luz, mas anjo caído...

Professora da Universidade Federal de São Paulo (UNIFESP). Pós-Doutorado pela Ecole des Hautes Etudes en Sciences Sociales, França. Brasileira, residente em São Paulo - SP. Email: 
investida se as condições de alteridade e de reciprocidade não forem suficientemente boas. Essas aparições se devem, pois, ao surgimento do sentimento de terror, que pode ser considerado como a mais extrema repulsa possível de experiência da visão da nossa morte psíquica." (p.140)

Terror da morte psíquica, quer dizer, da morte mais radical, e retiro para uma morte sublimada pela intervenção de demônios expressam que estes são companhias ou duplos. Se as aparições são sempre a presentificação de uma ausência, memórias de uma aparição, o vazio que se deixa preencher no presente, os demônios são o duplo invertido do corpo e da alma: não é a alma o duplo fantasmático do corpo, mas o corpo o reflexo fantasmático da alma: "Foi na feitura de um pacto escrito com tinta, depois com sangue, neste bojo transferencial, que se deu a evidência da alteridade do artista, uma abertura manifestada de forma bizarra. Este pacto faustiano propiciou alguma percepção da alteridade e implicou algum efeito de transformação no pintor Christoph Haizmann. Foi através dessa introdução da figura do demônio que o artista percebeu uma transformação em sua vida mental, e assim entrou em contato com representações próprias que lhe apareceram como um estranho. Este material estranho seria a atualização do inconsciente, que nas palavras de Versiani e Celes é um 'outro mim mesmo' ”.( Hardt Jr, 2013, p.137)

Há pois no acidioso uma questão epistemológica da maior importância que é a inversão das relações entre corpo e alma. Os demônios são a memória invadida pelo pensamento obsedante do pai desaparecido. Na rigorosa observância do luto, o pintor, por sua entrega à memória do pai, à sua assombração, aparta-se do comum dos homens e se exclui da vida comum. O pintor não pôde fazer a passagem da recordação patética da saudade para uma memorização mais definida segundo os códigos da memória institucionalizada, do código social que seria o trabalho do luto.

Os demônios e sua sublimação monástica são, assim, o mesmo: o difícil luto, a impossibilidade do luto de si mesmo. 


\section{REFERÊNCIAS}

Adorno,T. (2009), "Para uma Metacrítica da Razão Prática", in Dialética Negativa, trad. Marco Antonio Casanova, Ed. Zahar, RJ, 2009

Benjamim, W. (1984) Origem do Drama Barroco Alemão, trad. Sérgio Paulo Rouanet, ed Brasiliense,1984,pp 78-79.

Descartes,R. (1953), "Lettre à Chanut" de 6/06/1647, in Oeuvres et Lettres, Ed. Gallimard, 1953, p 1277.

Descartes,R. (1973) "Meditações", in Pensadores, trad.José Guoinsburg e Bento Prado Jr., ed Abril Cultural, 1973, p 94.

Dictionnaire Universel 1690 recuperado de http:gallica.bnf.fr em 21/02/2016.

Freud, S. (1976a). O estranho. In S. Freud. Edição standard brasileira das obras psicológicas completas de Sigmund Freud (J. Salomão, trad., Vol. 17, pp. 275314). Rio de Janeiro: Imago. (Trabalho original publicado em 1919).

Freud, S. (1976b). Uma neurose demoníaca do século XVII. In S. Freud. Edição standard brasileira das obras psicológicas completas de Sigmund Freud (J. Salomão, trad., Vol. 19, pp. 91-133). Rio de Janeiro: Imago Ed. (Trabalho original publicado em 1923).

Hardt Junior, O. (2013) "Uma neurose demoníaca do século XVII. Ide (São Paulo) 2013, vol.36, n.56 pp. 133-141.

Homero, (2008) Iliada, canto XXIII, vs 103-104, tradução Haroldo de Campos, ed. ARX, SP, 2008, p 2008, p. 395.

Koyré, (1967) Du monde clos à l'unviers infini, ed PUF,Paris,1967...p. 1-3.

Pasche, F. (1998) "Métaphysique et inconscient", Le sens de la psychanalyse, Puf, 1998 